\title{
AGE AND EXPERIENCE-RELATED DIFFERENCES IN BLOODCIRCULATION FUNCTIONING OF UNDERGROUND COAL MINERS
}

\author{
Bobko N. A.', Yabchanka R.Ya. ${ }^{2}$
}

IState Institution «Kundiiev Institute of Occupational Health of the National Academy of Medical Sciences of Ukraine», Kyiv

¿Lviv National Medical University named after Danylo Halytsky

Introduction. Every fourth case of acute diseases of the bloodcirculatory system in miners becomes fatal. Arterial hypertension (AH) is classified as an occupational disease. In those employed in underground work, the depth and rate of development of pathological processes exceed those of workers employed on the ground. The reasons for this situation are associated with a complex of harmful and dangerous factors in the working conditions of miners.

The purpose of the research was to identify some age and experience-related differences in bloodcirculation functioning in miners employed at underground coal mining enterprises.

Materials and research methods. 31 miners of 32-58 years $(43.5 \pm 1.2)$ with a total work experience of $13-28$ years (20.6 \pm 0.7$)$, underground shift work experience in the occupation $-8-22$ years (15.7 \pm 0.7$)$ were measured: heart rate (HR), systolic and diastolic blood pressure (BPS, BPD), height and weight. Haemodynamic indices, Kerdo's (VIK) and bloodcirculatory failure (BFI) indices were calculated, the type of bloodcirculation self-regulation was determined. Data were analyzed at the $\mathrm{p}<0.05$ level.

Results. According to the average group data, BPS and BPD were found in the zone of high norm, HR - at the upper limit of the norm, stroke volume (SV) and cardiac output $(\mathrm{CO})$ - in the zone of the «average» functional state of the bloodcirculatory system, peripheral vascular resistance (PVR) - in the «below average» zone, BFI - in the zone of tension of regulatory systems, VIK - in tendency to parasympathicotonia. $39 \%$ of miners showed BP in the zone of moderate AH, $6 \%$ - in medium AH, $100 \%$ - showed impaired self-regulation of bloodcirculation: $81 \%$ - by vascular type, $19 \%$ - by cardiac type. With an increase in age and experience, BPS, BPD, mean dynamic pressure, PVR increased, SV, CO decreased, and VIK decreased with age. With an increase in underground work experience, the asymmetry of BPD increased and the asymmetry of BPS decreased in miners. The functional state of the miners' bloodcirculatory system passed into the class of «below average» at the age of 48 , at a total work experience of 24 years, and at an underground work experience -18 years.

Conclusions. The miners showed an unfavourable state of the bloodcirculatory system: in $45 \%$ - increased BP corresponded to $\mathrm{AH}$, in $100 \%$ of the examined - impaired self-regulation of blood circulation, which is considered as a risk factor for the development of AH. The early transition of the functional state of the bloodcirculatory system to the «below average» class reflects the pronounced adverse effect of working conditions. An increase in BPD asymmetry and a decrease in BPS asymmetry $(\mathrm{p}<0.05)$ with an increase in underground work experience can be associated with the involvement of specific mechanisms of adaptation to work, in particular, cardiorenal. The identified isolated age-related increase in parasympathicotone is not consistent with the population norm and indicates the presence of adverse effects of a non-production origin, reflecting the need for comprehensive preventive measures to improve the working and living conditions of miners to extend their occupational longevity.

Key words: miners, underground work, shift work, night work, hypertension, parasympathicotonia, functional state of the bloodcirculatory system, harmful and dangerous working conditions

(C) Collective of authors, 2021 


\section{Introduction}

The pathology of the bloodcirculatory system is the cause of more than half of deaths worldwide and two out of three deaths in Ukraine [1]. Every fourth case of acute diseases of the bloodcirculatory system at the workplace among coal miners becomes fatal [2]. Arterial hypertension (AH) the pathological basis of strokes and heart attacks - is classified as an occupationally determined disease due to the relative risk and the etiological share of production factors in its development [3]. Diseases of the bloodcirculatory system in miners develop faster and are diagnosed at a younger age than on average in the population, the incidence of complications, life-threatening situations, disability due to the bloodcirculatory system pathology are higher [3, 4]. In underground workers, the depth and rate of development of pathological processes significantly exceeds those in ground workers: they have a higher cardiac risk [5], the prevalence of hypertension is significantly higher [3] and the relative risk of its development estimated as 8 -fold [4], the relative risk of developing atherosclerotic changes in the vascular wall, morphological restructuring of the myocardium and its valve apparatus is $3.5-12$ times higher [4], 20 times higher is the rate of decline in endothelial function - one of the main predictors of hypertension [5]. The reasons for the situation are associated with a complex of harmful and dangerous factors in the working conditions of miners, almost each of which is a risk factor for the development of the bloodcirculatory system diseases [6]: dust, an unfavorable microclimate, noise, vibration, the severity and intensity of the work performed, which under the underground work are more unfavorable and are aggravated by the lack of natural lighting, increased atmospheric pressure, its sharp drops when descending into the mine and ascending to the surface, hypogeomagnetic field, ionizing radiation, confined space at a high risk of explosions and fires with a threat to health and life, that leads to the development of chronic stress [2, $4,7]$. At the same time, the age-experience regularities of the dynamics of the state of the bloodcirculatory system in miners, which reveal effective directions for improving prophylaxis, remain insufficiently studied.

The purpose of the research was to identify some age and experience-related differences in bloodcirculation functioning in miners employed at underground coal mining enterprises.

\section{Materials and methods of research}

The research was carried out at the enterprises of the Lviv coal basin. The research protocols were approved by the Bioethics Committee of the State Institution «Kundiiev Institute for Occupational Health of National Academy of Medical Sciences of Ukraine». Practically healthy workers who signed informed consent were invited to participate in the studies. Thirty one miners (miner of the working face, spinner, mining underground) of the underground coal mines [men aged $32-58$ years old $\{M \pm \mathrm{m}$ : $(43.5 \pm 1.2)$ yrs $\}$ with the total work experience of $13-28$ years $\{(20.6 \pm 0.7)$ yrs $\}$ and underground work experience in the occupation - of $8-22$ years $\{(15.7 \pm 0.7)$ yrs $\}$ ] working rotating 6 -h shifts during a 6 -day working week were observed at prophylaxis examination in the hospital (during day time, one observation per worker) by measured height, weight; heart rate (HR), blood pressure systolic and diastolic (BPS, BPD) in the upper extremities using digital blood pressure monitor DS-1902 «Nissei».

Hemodynamic parameters were calculated: Pulse Pressure $(\mathrm{PP}=\mathrm{BPS}-\mathrm{BPD})$, MeanDynamic Pressure $(\mathrm{MDP}=0.42 \cdot \mathrm{PP}+\mathrm{BPD})$, Stroke Volume $(\mathrm{SV}=100+0.5 \cdot \mathrm{PP}-0.6 \cdot$ $\mathrm{BPd}-0.6 \cdot$ Age), Cardiac Output $(\mathrm{CO}=\mathrm{SV} \cdot$ HR), Periphery Vascular Resistance (PVR = 
MDP • $1333 \cdot 60 / \mathrm{CO})$ ), Kerdo's Vegetative Index $(\mathrm{KVI}=(1-\mathrm{BPD} / \mathrm{HR}) \cdot 100 \%)[8]$, Bloodcirculatory Failure Index (BFI = BPS/HR) [9]. Bloodcirculation self-regulation type was defined [10].

Blood pressure levels were evaluated using WHO-ISH Guidelines (1999) [11]. SV, CO and PVR levels were assessed using Buzunov's Classification (1991) [12]. The bloodcirculatory system functional state was evaluated as a mean of these three parameter assessments [13]. Blood pressure asymmetry was defined when the difference in BPS or BPD scores between left and right hands was higher than $10 \mathrm{~mm} \mathrm{Hg}$ [14].

The data were analysed at $p<0.05$ using basic statistics and Pearson correlation (Ms Excel 2007). A mathematical model of the linear regression analysis was applied.

\section{Results}

According to the mean group data, in miners systolic and diastolic blood pressure parameters were found in the high norm zone [11], the pulse - in the zone of the upper boundary of the norm [15] (Table 1). Parameters of SV and $\mathrm{CO}$ were found in the «middle class» of the functional state of the bloodcirculatory system, the PVR - in the «below the average» class - according to the classification of V. A. Buzunov [12]. BFI reflected the strain in the regulatory systems of the bloodcirculatory system functioning [16], VIK - tendency to parasympaticotone [8]. The asymmetry of arterial blood pressure on the upper limbs was found in the zone of the norm [14].

Analysis of individual data has shown that $45 \%$ of the surveyed manifested blood pressure in the

Table 1

Parameters of the bloodcirculatory system functioning in miners $(\mathrm{N}=31)$

\begin{tabular}{|c|c|c|c|c|c|c|}
\hline № & $\begin{array}{c}\text { Parameter } \\
\text { of bloodcirculatory }\end{array}$ & Min & Max & $\mathbf{M} \pm \mathbf{m}$ & $\begin{array}{l}\text { Qualification of the } \\
\text { mean group value } \\
\text { of the parameter }\end{array}$ & References \\
\hline 1 & BPS - left hand (mm Hg) & 120 & 150 & $136 \pm 1$ & high norm & WHO Guidance,1999 \\
\hline 2 & BPD - left hand (mm Hg) & 70 & 100 & $86 \pm 1$ & high norm & WHO Guidance, 1999 \\
\hline 3 & HR - left hand (beat/min.) & 68 & 88 & $80 \pm 1$ & norm (top) & \\
\hline 4 & $\begin{array}{l}\text { BPS - right hand } \\
(\mathrm{mm} \mathrm{Hg})\end{array}$ & 115 & 150 & $132 \pm 1$ & high norm & WHO Guidance, 1999 \\
\hline 5 & $\begin{array}{l}\mathrm{BPD}-\text { right hand } \\
(\mathrm{mm} \mathrm{Hg})\end{array}$ & 70 & 95 & $85 \pm 1$ & high norm & WHO Guidance, 1999 \\
\hline 6 & $\begin{array}{l}\text { BPS difference at left and } \\
\text { right hands (mm Hg; abs) }\end{array}$ & 0 & 5 & $4.5 \pm 1.0$ & norm & $\begin{array}{l}\text { Cheremisina A. Yu. } \\
\text { et al., } 2013\end{array}$ \\
\hline 7 & $\begin{array}{l}\text { BPD difference at left and } \\
\text { right hands (mm Hg; abs) }\end{array}$ & 0 & 5 & $1.5 \pm 1.0$ & norm & $\begin{array}{l}\text { Cheremisina A. Yu. } \\
\text { et al., } 2013\end{array}$ \\
\hline 8 & $\mathrm{SV}(\mathrm{ml})$ & 33,7 & 61,4 & $47.40 \pm 1.44$ & middle class & Buzunov V. A., 1991 \\
\hline 9 & $\mathrm{CO}(\mathrm{ml})$ & 2831 & 4748 & $3783 \pm 102$ & middle class & Buzunov V. A., 1991 \\
\hline 10 & $\operatorname{PVR}(\mathrm{kPa} \bullet \mathrm{s} / \mathrm{l})$ & 1737 & 3101 & $2327 \pm 82$ & class below middle & Buzunov V. A., 1991 \\
\hline 11 & VIK (c. u.) & $-20,5$ & 2,4 & $-7.30 \pm 1.75$ & norm & Kérdö I., 1966 \\
\hline 12 & BFI (c. u.) & 1,5 & 1,93 & $1.70 \pm 0.02$ & $\begin{array}{l}\text { strain in regulatory } \\
\text { systems }\end{array}$ & $\begin{array}{l}\text { Tebenova K. S., } \\
\text { et al., } 2015\end{array}$ \\
\hline
\end{tabular}


hypertension zone: $39 \%$ - in the zone of moderate hypertension, $6 \%$ - in the zone of medium hypertesnion. The normal type of bloodcirculation self-regulation has been found in nobody. The vascular type of blood circulation self-regulation was revealed in $81 \%$ of the surveyed, cardiac one - in $19 \%$. Asymmetry of systolic or diastolic blood pressure ( $>10 \mathrm{~mm} \mathrm{Hg}$ ) has been detected in no miner.

Age and experience-dependent significant increase in BPS, BPD, MDP, PVR, age and experience-dependent significant decrease in $\mathrm{SV}$, $\mathrm{CO}$ and age reduction in VIK (increase in parasympathetic severity) were revealed.

The significant negative correlation of the underground experience in the occupation with the difference in BPS on the upper limbs was found, positive one - with the difference of BPD, in the absence of the significant correlation with age or total work experience (Table 2).

The functional state of the bloodcirculatory system of miners passes to the class «below average» (according to the classification of V. A. Buzunov, 1991) at the age of 48 years old, at a total work experience - of 24 years, at the underground experience in the occupation - of 18 years (Table 3 ). The functional state of the bloodcirculatory system of miners passes from the class «below average» to the «low» class at the age of 52 years old, at a total work experience - of 27 years, hypothetically - at the underground experience in the occupation - of 57 years. Hypothetically the functional state of the bloodcirculatory system of miners could move into the «very low» class at the age of 60 years old or at the total work experience of 32 years. In practice, miners at the age of more than 58 years old or at the total work experience for more than 28 years or more than 22 years of underground experience in the occupation in our sample were not identified.

Table 2

Correlation of the parameters of the bloodcirculatory system functioning with age and work experience of miners $(\mathrm{N}=31, \mathrm{p}<0.05)$

\begin{tabular}{|c|c|c|c|}
\hline Parameter & Age & $\begin{array}{c}\text { Total } \\
\text { work } \\
\text { experience }\end{array}$ & $\begin{array}{l}\text { Underground } \\
\text { shift work } \\
\text { experience } \\
\text { in miner } \\
\text { occupation }\end{array}$ \\
\hline BPS - left hand & 0.42 & 0.40 & \\
\hline BPD - left hand & 0.50 & 0.44 & \\
\hline BPS - right hand & 0.41 & 0.46 & \\
\hline $\mathrm{BPD}$ - right hand & 0.52 & 0.36 & \\
\hline BPS difference & & & -0.41 \\
\hline BPD difference & & & 0.39 \\
\hline SV & -0.80 & -0.60 & \\
\hline $\mathrm{CO}$ & -0.81 & -0.60 & \\
\hline $\begin{array}{l}\text { Mean dynamic } \\
\text { pressure }\end{array}$ & 0.50 & 0.46 & \\
\hline $\begin{array}{l}\text { Peripheral vascu- } \\
\text { lar resistance }\end{array}$ & 0.80 & 0.62 & \\
\hline $\begin{array}{l}\text { Vegetative index } \\
\text { of Kerdo }\end{array}$ & -0.38 & & \\
\hline
\end{tabular}

\section{Discussion}

According to the mean group data, papameters of the bloodcirculatory system functioning in miners are located at the upper boundaries of the physiological norm, which could reflect the certain degree of a strain in the system functioning, as evidenced by the BFI in the strain zone - on the background of «average» - «below the average» class of the functional state of the bloodcirculation system.

VIK in the zone of negative values indicates a tendency to parasympaticotone that, according to the literature, is associated with an increase in stress and a decrease in the adaptive reserves of the bloodcirculatory, nervous and sympatheticadrenal systems [17-19], with the development of fatigue [16] or prepathological states under unfa- 
Age and experience-related changes in the functional state of the bloodcirculatory system in miners (according to the classification of V. A. Buzunov, 1991)

\begin{tabular}{|l|c|c|c|}
\hline Pass to the class & Age (years) & Total work experience (years) & $\begin{array}{c}\text { Underground shift work experience } \\
\text { (years) }\end{array}$ \\
\hline Below mean & 48 & 24 & 18 \\
\hline Low & 52 & 27 & $>40$ \\
\hline Very low & 60 & 32 & $>40$ \\
\hline
\end{tabular}

vourable ecology [20], is characteristics of persons engaged in tension labour, shift and night work $[16,21,22]$.

The impaired bloodcirculatory self-regulation is a prognostically unfavorable sign indicating the high risk of arterial hypertension development in miners [10], which is consistent with the literature data on its occupational conditionality [3] and prevalence among miners [23].

The identified age and experience-dependent significant decrease in $\mathrm{SV}$ and $\mathrm{CO}$ with an increase in PVR, BPS, BPD, MDP is consistent with the literature data on the age-related weakening in the pump function of the heart, the loss of elasticity and hypertrophy of large arterial vessels, reducing the volume of blood flow [24, 25].

The revealed age reduction in VIK (amplification of parasympaticotone) in the absence of a significant correlation with the work experience does not have a simple correlate in the literature. It is known that the population rate is the age-related increase in sympathetic tone [25] - as an adaptive body reaction to the previous environment conditions against the background of an age reduction of high-speed functions. According to our data, an increase in work experience in the occupations of intense mental operator work has been associated with a decrease in VIK, while the age reduction in VIK was noted only in the first night shifts with a high production load [22]. Hence, the age-related strengthening in para- sympaticotone in miners probably should be linked not so much to the specifics of working conditions, as to the circumstantial factors (possibly to unfavourable living conditions, harmful habits, low educational level, etc. [7]).

It was revealed that with an increase in the underground shiftwork experience of miners, the asymmetry of diastolic blood pressure increases and the asymmetry of systolic blood pressure decreases, that may indicate the involvement of specific adaptation mechanisms to the underground working conditions of miners, in particular - to high levels of noise and vibration, possibly at night, by involving cardio-renal mechanisms [26].

The transition of the functional state of the bloodcirculatory system in miners to the «below average» class at the age of 48 years old, at a total work experience of 24 years or under the underground experience in the occupation of 18 years, it is evidences on the adverse working conditions leading to the early deterioration of the bloodcirculatory system in miners, and the need to apply comprehensive measures to improve the conditions of their work and life to preserve the employment potential and to extent their occupational longevity.

\section{Conclusions}

1. The miners showed the unfavourable state of the bloodcirculatory system: $45 \%$ - manifested an increased blood pressure corresponding to the hypertension of moderate 
(in $39 \%$ ) or the average (in $6 \%$ ) stage, all $100 \%$ of the examined - showed an impaired bloodcirculatory self-regulation ( $81 \%$ - by the vascular type, $19 \%$ - by cardiac), which is considered in the literature as a risk factor for the arterial hypertension development.

2 . The functional state of the bloodcirculatory system in underground coal miners passes to the «below average» class at the age of 48 , at a total work experience of 24 years or at the underground experience with systematic night shifts - of 18 years, which reflects the pronounced adverse effect of underground shift work of miners onto the functional state of the bloodcirculatory system and substantiates the preferential age of their retirement.

\section{References}

1. Statystychnyy shchorichnyk Ukrayiny 2019. [Statistical Yearbook of Ukraine 2019]. The State Statistics Service of Ukraine, edited by I. Ye. Verner. Kyiv, 2020, 465 p. URL: http://ukrstat.gov.ua/druk/publicat/ kat_u/ 2020/zb/11/zb_yearbook_2019.pdf.

2. Bukhtiyarov I. V., Golovkova N. P., KhelkovskiySergeyev N. A., Kotova N. I. (2018). "Causes and measures to prevent the sudden death of workers in mines during coal mining", Aktual'nyye problemy meditsiny truda: Sbornik trudov instituta [Actual problems of labour medicine: A collection of works of the Institute], 1, 341-350. https://doi.org/ 10.31089/978-5-907035-94-2-2018-1-341-350.

3. Karabalin S. K., Karabayeva R. Zh., MazhitovT. M. (2009), "Production conditionality of arterial hypertension in miners", Byulleten' VostochnoSibirskogo nauchnogo tsentra SO RAMN, 1, 118-121.

4. Ustinova O. Yu., Vlasova Ye. M., Nosov A. Ye. et al. (2018), "Assessment of the risk of cardiovascular disease development in miners engaged in underground mining of chrome ore", Analiz riska zdorov'yu, 3, 94-103. https://doi.org/10.21668/ health.risk/2018.3.10.

5. Shlyapnikov D. M., Shur P. Z., Vlasova Ye. M. et al. (2015), "Occupational risk to develop the circulatory system diseases in workers employed in underground mining", Meditsina truda i prom. ekologiya, 8, 6-9.
3. With an increase in the underground shift work experience of miners, the asymmetry of diastolic blood pressure increases and the asymmetry of systolic blood pressure decreases $(p<0.05)$, which can be associated with the involvement of specific adaptation mechanisms to work of miners in harmful and hazardous conditions, in particular, through involvement of cardio-renal mechanisms.

4. The identified isolated age-related increase in parasympathicotone is not consistent with the population norm and indicates the presence of unfavourable imperatives of non-productive origin, reflecting the need for integrated preventive measures to improve the working and living conditions of miners to preserve the employment potential and to extend their occupational longevity.

6. Babanov S. A. (2020), Professional'nyye porazheniya serdechno-sosudistoy sistemy rabotnikov [Occupational damage to the cardiovascular system of workers]. GBOU VPO «Samarskiy gosudarstvennyy meditsinskiy universitet» MZ RF. 12 p. URL: https:// www.trudcontrol.ru/press/publications/25775/ professionalnie-porazheniya-serdechno-sosudistoysistemi-rabotnikov.

7. Maksimov S. A., Skripchenko A. Ye., Artamonova G. V. (2014), "Comparative analysis of the prevalence of cardiovascular risk factors in miners in Western Siberia with all-Russian data", Profilakticheskaya meditsina, 2, 30-34.

8. Kérdö I. (1966), «Ein aus Daten der Blutzirkulation kalkulierter Index zur Beurteilung der vegetativen Tonuslage von I. Kérdö", Acta neurovegetativa, 29 (2), 250-268. https://doi.org/ 10.1007/BF01269900.

9. Khramov Yu. A. and Veber V. R. (1985), Vegetativnoye obespecheniye i gemodinamika pri gipertonicheskoy bolezni [Vegetative maintenance and hemodynamic under hypertensive disease]. Nauka, Novosibirsk, Russia.

10. Arinchin N. I. and Kulago G. F. (1969), Gipertonicheskaya bolezn' kak narusheniye samoregulaytsii krovoobrascheniya [Hypertensive disease as a disorder of blood circulation]. Nauka i tekhnologiya, Minsk, Belarus.

11. Chalmers J., MacMahon S., Mancia G. et al. (1999), «World Health Organization-International 
ISSN 2223-6775, Ukrainian Journal of Occupational Health, 2021, 17 (3), 175-181

Society of Hypertension Guidelines for the management of hypertension. Guidelines subcommittee of the World Health Organization", Clin. Exp. Hypertens., 21 (5-6), 1009-1060. https://doi. org/ 10.3109/10641969909061028.

12. Buzunov V. A. (1991), Proizvodstevennye factory i vozrastnaya rabotosposobnost' [Production factors and aged work ability]. Zdorov'ya, Kiev, Ukraine.

13. Bobko N. A. (2002), "State of the cardiovascular system in electricity distribution network controllers", Meditsina truda i prom. ekologiya, 3, 8-12.

14. Cheremisina A. Yu., Saifutdinov R. G. and Ismagilov M. F. (2013), "Comparative analysis of parallel double daily monitoring of arterial blood pressure in shoulder arteries in patients with hypertension of the I, II stages", Vestnik sovremennoy klinicheskoy meditsiny, 6 (5), 31-34. https://doi. org/10.20969/VSKM.2013.6(5).31-34.

15. Human pulse: the norm for ages. URL: https:// puls-msk.ru/puls-cheloveka/.

16. Tebenova K. S., Ilyasova B. I., Zarkenova Zh. T. and Zarkenova L. S. (2015), "Functional state of the bloodcirculatory system in employees of video display terminals in shift dynamics". Uspekhi sovremennogo yestestvoznaniya, 1, 382-387.

17. Vorona A. A., Golovkina O. L., Matyukhin V. V., Yushkova O. I. (1999), "Influence of occupational factors on the clinical and physiological status of persons working with video display terminals", Meditsina truda i prom. ekologiya, 7, 25-28.

18. Tkachenko L. M., Perederiy H. S. (2000), "Vegetative correlates of emotional stress in persons with different states of the autonomic nervous system", Fiziolohichnyy zhurn, 46 (6), 61-67.
19. Sato S., Taoda K., Kawamura M. et al. (2001), "Heart rate variability during long truck driving work", J. Hum. Ergol. 30, 1-2, 235-240.

20. Shadetova A. Zh., Kaliyeva I. A., Alshynbekova G. K., Shokabayeva A. S. (2016), «Pre-nosological status of the population living in the Aral Sea region", Nauchnoye obozreniye. Meditsinskiye nauki. 3, 142-144. URL: https://science-medicine.ru/ru/article/view?id=901.

21. Bobko N. A., Dovgopola S. P. (2021), «Biological age and cognitive functions in surgeons under roundo-clock duties", Ukrainian Journal of Occupational Health, 17 (1), 35-52. https://doi.org/10.33573/ ujoh2021.01.035.

22. Bobko N. A. (2010). "Age changes in mental activity and blood circulation in human-operators of intense shift work", Problemy stareniya i dolgoletiya, 19 (1), 66-89.

23. Martynova N. A., Kislitsyna V. V. (2017), «Occupational morbidity in miners (literature review)", Zdorov'ye. Meditsinskaya ekologiya. Nauka. 5, 46-52. https://doi.org/10.5281/zenodo. 1115460.

24. Frol'kis V. V., Shevchuk V. G. (1982), "Hemodynamics and its regulation during aging". Fiziologicheskiye mekhanizmy stareniya [Eds: D. F. Chebotarev, V. V. Frol'kis], Leningrad, Nauka, 107-119.

25. Ferrari A. U. (2002), "Modifications of the cardiovascular system with aging», Am. J. Geriatr. Cardiol., 11 (1), 30-33. https://doi.org/10.1111/ 1467-8446.00044-i1.

26. Melent'yev A. V., Denisova Ye. A. (2015), "Developmen of cardiorenal pathology in workers in contact with the noise and vibration factor", Meditsina truda i prom. ekologiya, 9, 93-94.

\section{ORCID ID of co-authors and their contributions:}

Bobko N. A. (ORCID ID 0000-0002-4545-7421) - problem statement, development of research methodology, review of literature, data analysis, text writing, conclusion formulation;

Yabchanka R. Ya. (ORCID ID 0000-0001-5457-7479) - research organization, primary material collection, data base preparation.

Information about sources of financing of the research: the research has been carried out on the topic «Features of age changes of human functional body state under non-standard work regimes», No. of state registration $0119 \mathrm{U} 100585$.

Received: August 5, 2021

Accepted for publication: September 6, 2021

Contact Person: Bobko Natalia Andriivna, Doctor of biological sciences, Laboratory of Hygiene and Physiology of Shift Work, State Institution «Kundiiev Institute of Occupational Health of the National Academy of Medical Sciences of Ukraine», 75, Saksaganskogo str, Kyiv, 01033. Tel: + 3804428946 05. E-mail: nbobko@bigmir.net 